\section{Learning Science}

\section{August-1 September 2005 Barcelona, Spain}

One of the goals of the European Science Education Research Association (ESERA), which was formed in 1995, is to enhance the quality and range of research training in science education in Europe. With this in mind, a conference on Contributions of Research to Enhancing Students' Interest in Learning Science will be held 28 August-1 September 2005 in Barcelona, Catalonia, Spain.

This specific aim of the event is to highlight particular research achievements dealing with declining interest among European students in studying science and technology. Strong interest in this topic has led to a major increase in research that could provide a useful guide for future political decisions. The conference is an ideal opportunity to promote and facilitate the dissemination, transfer, use, and assessment of these research results. Another aim of the conference is to support the career development and training of new generations of researchers in the field of science education.

The ESERA-CRESILS Conference has a specifically designed program for early researchers that includes general conferences, presentations by expert researchers, presentations by the early researchers in guided sessions, workshops, open discussions with editors of research journals, and presentation of relevant EU programs.

The conference subtopics are as follows:

- reconceptualizing the curriculum

- enhancing scientific thinking fostering scientific attitudes towards natural phenomena and everyday

teaching models and strategies for science classes

- developing research-based innovative units for primary, secondary, or university students

- developing research-based proposals for teacher education and professional development

- assessment of science learning

- integrating communication and informatics technologies in science curriculum

- communication and public understanding of science

- understanding the nature of science; epistemological and historical patterns

- environmental education and field studies

- informal and non-formal contexts for science teaching and learning

- science and the media, images of science

- model/based teaching and learning

- laboratory/based practices for science teaching and learning

- bridging the gender gap

- science in early childhood

\section{Deadlines}

Deadline for proposals: January 2005

Confirmation of proposal acceptance: April 2005

Deadline for advance registration: 15 May 2005

Final program: July 2005

See calendar on page 40 for contact information

www.esera2005-cresils.net

\section{Molten Salts, Chemistry, and Technology}

\section{August-2 September 2005 \\ Toulouse, France}

Ionic liquids in general include traditional high-temperature molten salts, metal-molten salt systems, glass-forming systems, and novel room-temperature melts. At the 7th International Symposium on Molten Salts, Chemistry, and Technology, several state-ofthe-art applications will be presented that highlight the importance of these ionic liquids in various industries (batteries, nuclear energy, pyrochemical reprocessing of nuclear fuel, synthesis, catalysis, etc.).

Lectures at the symposium will detail and describe the structure, dynamics, electrochemistry, interfacial, and thermodynamic properties of the relevant experimental methods. Such fundamental concepts are essential for an in-depth understanding of the general physicochemical properties of these Coulomb liquids. Experimental methods for investigating structural, dynamic, electrochemical, thermodynamic, and interfacial properties will be detailed. Techniques for data collection and analysis will also be discussed. This meeting will provide a forum to discuss the transfer of these methods and techniques developed for hightemperature, as well as the more recent room-temperature, melts.

\section{http://inpact.inp-toulouse.fr/progep/MS7/}

